\title{
ANALISIS MERKURI DAN HIDROKUINON PADA KRIM PEMUTIH YANG BEREDAR DI BLITAR
}

\author{
Analysis of Mercury and Hydroquinone \\ in Whitening Cream in Blitar
}

\author{
Afidatul Muadifah*1 ${ }^{1}$ Khoirul Ngibad ${ }^{2}$ \\ ${ }^{1}$ stikes Karya Putra Bangsa, Tulungagung \\ ${ }^{2}$ Universitas Ma'arif Hasyim Latif, Sidoarjo \\ *email: afyda31@gmail.com
}

\begin{abstract}
Abstrak. Merkuri dalam konsentrasi kecil dapat menyebabkan racun. Hidrokuinon dapat menyebabkan kanker, sehingga dilarang penggunaannya dalam krim pemutih. Tujuan penelitian ini yaitu: mengidentifikasi merkuri dan hidrokuinon pada krim pemutih, mengetahui kadar hidrokuinon dalam krim pemutih, dan menentukan validasi metode analisis hidrokuinon pada krim pemutih di Blitar. Metode penelitian, identifikasi keberadaan merkuri dan hidrokuinon pada krim pemutih dilakukan secara kualitatif dan penetapan kadar hidrokuinon secara kuantitatif menggunakan spektrofotometer UV-Vis. Hasil uji kualitatif pada 12 sampel, ada 8 sampel yang positif mengandung merkuri dan hidrokuinon. Hasil uji kuantitatif dengan menggunakan instrumen Spektrofotometer UV-Vis 12 sampel positif mengandung hidrokuinon dengan kadar P1 0,0735 ppm; P2 0,727 ppm; P3 0,025 ppm; P4 0,021 ppm; P5 0,030 ppm; P6 0,044 ppm; P7 0,131 ppm; P8 1,188 ppm; P9 0,002 ppm; P10 0,840 ppm; P11 0,039 ppm; dan P12 0,030 ppm. Perolehan nilai presisi $0,872 \%$, akurasi $97,5 \%$, LOD 3,373 ppm dan LOQ $6,704 \mathrm{ppm}$. Kadar hidrokuinon pada semua sampel <200 ppm sehingga masih ditolerir oleh BPOM.
\end{abstract}

Kata kunci: merkuri, hidrokuinon, krim pemutih, Blitar, spektrofotometer UV-Vis

Abstract. Mercury in small concentration may cause toxins. Hydroquinone may cause cancer, so that it is prohibited to use it in whitening creams. The purposes of this research were: identifying mercury and hydroquinone in whitening creams, finding out the hydroquinone levels in whitening creams, and determining the validation of the analytical method of hydroquinone content in the whitening cream in Blitar. The research method was that the identification of mercury and hydroquinone presence in whitening creams was done qualitatively; and quantitative determination of hydroquinone levels used a UV-Vis spectrophotometer. Qualitative test results on 12 samples were 8 positive samples out of it contained mercury and hydroquinone. Quantitative test results using the $U V$-Vis Spectrophotometer instrument showed that 12 positive samples contained hydroquinone at levels: P1 0,0735 ppm; P2 0,727 ppm; P3 0,025 ppm; P4 0,021 ppm; $P 5$ 0,030 ppm; $P 6$ 0,044 ppm; $P 7$ 0,131 ppm; P8 1,188 ppm; P9 0,002 ppm; $P 10$ 0,840 ppm; P11 0,039 ppm; and P12 0,030 ppm. The acquisition of precision value was $0.872 \%, 97.5 \%$ for accuracy, LOD was 3.373 ppm and LOQ was 6.704 ppm. The hydroquinone levels in all samples were <200 ppm so that they were still well tolerated by BPOM 
Keywords: $\begin{gathered}\text { mercury, hydroquinone, whitening cream, Blitar, UV-Vis } \\ \text { Spectrophotometer. }\end{gathered}$

\section{PENDAHULUAN}

Sediaan kosmetik atau lebih trend dikenal dengan istilah krim pemutih, yang berfungsi sebagai pemutih kulit masih beredar sebagai produk yang digemari, oleh karena itu bahan-bahan yang dapat digunakan sebagai pemutih kulit banyak diteliti dan dikembangkan. Salah satu bahan pemutih kulit yang terkenal dan telah banyak digunakan adalah merkuri dan hidrokuinon (Draelos \& Thaman, 2005).

Merkuri termasuk logam berat berbahaya yang dalam konsentrasi kecil dapat bersifat racun. Logam berat dapat menghambat kerja enzim apabila terakumulasi di dalam tubuh organisme sehingga proses metabolisme terganggu, selain itu juga menyebabkan alergi, mutagen, teratogen atau karsinogen bagi manusia (Vouk, 1986). Efek dari pemakaian merkuri ini dimulai dengan munculnya bintik-bintik hitam pada kulit dan akhirnya mengakibatkan alergi serta iritasi kulit (BPOM, 2008). Hidrokuinon sebagai bahan aktif pemutih kulit bekerja melalui mekanisme efek toksik hidrokuinon terhadap melanosit (sel tempat sintesis melanin/pigmen hitam pada kulit) dan melalui penghambatan melanogenesis (proses pembentukan melanin) (Westerhof \& Kooyers, 2005).

Berdasarkan pemeriksaan yang dilakukan oleh Balai Pengawasan Obat dan Makanan (BPOM), mayoritas produk krim pemutih yang beredar lebih banyak mengandung hidrokuinon dan merkuri. Dalam Peraturan Kepala Badan Pengawasan Obat dan Makanan nomor KH.03.1.23.08.11.07517 tahun 2011 tentang Persyaratan Teknis Bahan Kosmetika Hidrokuinon telah dilarang digunakan sebagai pemutih dalam kosmetik. Hidrokuinon hanya digunakan sebagai kosmetik untuk kuku artifisial dengan kadar 0,02\% (BPOM, Peraturan Kepala Badan Pengawas Obat dan Makanan Repubkik Indonesia Nomor HK.03.1.23.11.07331, 2011). Sedangkan merkuri tidak boleh ditambahkan ke dalam kosmetik sama sekali. Karena merkuri dan senyawanya termasuk dalam daftar kosmetik yang dilarang, sesuai lampiran I Peraturan Kepala Badan POM No. HK.00.05.42.1018 Tahun 2008 tentang bahan kosmetik maka produk yang beredar harus diperhatikan. Tetapi dari beberapa penelitian yang sudah dilakukan, ditemukan kandungan merkuri dan hidrokuinon dalam krim pemutih di beberapa daerah. Merkuri ditemukan pada produk krim pemutih yang beredar di Kabupaten Tulungagung (Hermawati \& Lathifah, 2019), Bandung (Syafnir \& Putri, 2011), dan Manado (Parengkuan dkk., 2013) serta ditemukannya kandungan hidrokuinon dalam produk krim pemutih di Kediri (Lailul \& Cikra, 2015), Surabaya (Arifiyana dkk., 2019), dan Yogyakarta (Astuti dkk., 2016).

Melihat uraian di atas, penelitian ini penting dilakukan guna memastikan keamanan krim pemutih yang beredar di Blitar, mengingat banyaknya konsumen yang telah menggunakannya. Tujuan penelitian ini yaitu: untuk mengidentifikasi merkuri dan hidrokuinon pada krim pemutih di Blitar, mengetahui kadar hidrokuinon dalam krim pemutih di Blitar, dan menentukan validasi metode analisis yang digunakan pada penetapan kadar hidrokuinon pada krim pemutih di Blitar. 


\section{METODE PENELITIAN Alat dan Bahan}

Alat yang digunakan dalam penelitian adalah timbangan analitik, alat gelas, bunsen, kawat tembaga, amplas, plat tetes, penangas air, penangas es, pipa kapiler, Lampu $\mathrm{UV}_{254} \mathrm{~nm}$, Spektrofotometer UV-Vis Inesa UV/Vis N4S, mikro pipet.

Bahan yang digunakan adalah kalium iodida $(\mathrm{KI}) 0,5 \mathrm{~N}$, asam nitrat pekat $\left(\mathrm{HNO}_{3}\right)$, asam klorida pekat $(\mathrm{HCl})$, akuadest, floroglusin $1 \%$, baku pembanding hidrokuinon, besi (III) klorida $\left(\mathrm{FeCl}_{3}\right), \mathrm{NaOH}$, etanol $96 \%$, toluen, asam asetat glasial, plat KLT 60 F254.

\section{Langkah Penelitian}

Penelitian ini dilakukan secara eksperimental yaitu suatu metode yang digunakan untuk menganalisis suatu hasil penelitian seperti untuk mengetahui keberadaan merkuri (Hg) pada sediaan krim pemutih wajah dengan melakukan percobaan. Uji kualitatif merkuri dilakukan dengan dua metode uji yaitu uji warna KI dan uji nyala api, sedangkan uji kualitatif hidrokuinon dilakukan dengan uji pereaksi warna $\left(\mathrm{FeCl}_{3}\right)$ dan dilanjutkan dengan pengujian secara kuantitatif menggunakan Spektrofotometer UV-Vis. Metode yang digunakan selanjutnya dilakukan uji validasi metode guna mengetahui tingkat validitasnya dengan mengukur empat parameter validasi, yaitu tingkat linieritas, akurasi, presisi, Limit of Detection (LOD) dan Limit of Quantitation (LOQ).

Sampel yang digunakan pada penelitian ini adalah krim pemutih yang diambil dari toko kosmetik di Blitar. Teknik pengambilan sampel dalam penelitian ini adalah pengambilan sampel secara acak. Pengambilan sampel secara acak adalah cara pengambilan sampel yang memberikan kesempatan yang sama untuk diambil kepada setiap elemen populasi yang mana dalam penelitian ini berdasarkan nomor urut ganjil dari daftar produk krim pemutih yang beredar di Blitar.

\section{HASIL DAN PEMBAHASAN}

Penelitian tentang analisis merkuri dan hidrokuinon pada krim pemutih telah banyak dilakukan, dan hasil penelitian tersebut menunjukkan positif adanya kandungan dua bahan berbahaya tersebut (Armin dkk., 2013) (Astuti dkk., 2016) (Syafnir \& Putri, 2011) (Parengkuan dkk., 2013) (Chakti dkk., 2019).

Sampel krim pemutih yang di ambil secara acak dari toko kosmetik sebanyak 12 buah. Sampel yang telah diperoleh diberikan label P1 s/d P12.

\section{Uji Kualitatif Merkuri}

Analisis kualitatif merkuri dengan pereaksi warna KI dilakukan dengan menambahkan $\mathrm{HNO}_{3}$ pekat ke dalam larutan sampel untuk melarutkan logam berat merkuri, karena secara kimia logam merkuri reaktif dengan $\mathrm{HNO}_{3}$ pekat (Vogel, 1985). Reaksi antara logam merkuri dengan $\mathrm{HNO}_{3}$ pekat sebagai berikut: $\mathrm{Hg}(\mathrm{s})+2 \mathrm{NO}_{3}^{-}(\mathrm{aq})+$ $4 \mathrm{H}^{+}{ }_{(\mathrm{aq})} \rightarrow \mathrm{Hg}^{2+}{ }_{(\mathrm{aq})}+2 \mathrm{NO}_{2(\mathrm{~g})}+2 \mathrm{H}_{2} \mathrm{O}_{(\mathrm{l})}$

Delapan sampel krim pemutih menunjukkan hasil positif pada uji pereaksi warna KI (0,5 N), ditunjukkan dengan terbentuknya endapan $\mathrm{HgI}_{2}$ (merkuri (II) Iodida) yang berwarna merah kehitaman. Reaksi antara Ion merkuri $\left(\mathrm{Hg}^{2+}\right)$ dengan KI sebagai berikut: $\mathrm{Hg}^{2+}{ }_{(\mathrm{aq})}+2 \mathrm{KI}_{(\mathrm{aq})} \rightarrow \mathrm{HgI}_{2(\mathrm{~s})}+2 \mathrm{~K}_{(\mathrm{aq})}$ 
Analisis merkuri dengan uji nyala api menunjukkan hasil yang positif pada 8 sampel yang ditandai dengan adanya warna hijau kebiruan. Warna tersebut menunjukkan warna komplementer sampel adalah merah. Pada prinsipnya, suatu senyawa kimia yang dipanaskan akan terurai menjadi unsur-unsur pembentuknya yaitu dalam bentuk gas atau uap. Sejumlah energi tinggi akan diserap oleh atom-atom dari unsur logam tersebut (keadaan tereksitasi). Pada keadaan tereksitasi ini, sifat atom logam menjadi tidak stabil sehingga mudah kembali pada keadaan energi rendah (dengan memancarkan kembali energi yang telah diserap). Panjang gelombang yang khas dari setiap atom unsur logam, bergantung pada besarnya energi yang diserap atau dipancarkan, sehingga menghasilkan warna komplementer, yaitu warna yang tampak oleh mata manusia. Hal tersebut ditunjukkan dengan warna nyala yang dari atom unsur logam.

Merkuri terakumulasi dalam tubuh karena tubuh telah terpapar oleh bahan berbahaya tersebut. Masuknya merkuri ke dalam tubuh melalui kulit, kemudian akan terabsorbsi menjadi merkuri divalent $\left(\mathrm{Hg}^{2+}\right)$ dengan bantuan enzim katalase. Merkuri dapat dengan singkat memutihkan kulit, melalui mekanisme penghambatan melanin. Merkuri dapat menimbulkan gejala simptomatik apabila kadarnya melebihi batas tolerasi, yaitu $>4 \mu \mathrm{g} / \mathrm{L}$ dalam urin manusia (WHO).

Tabel 1. Hasil uji kualitatif merkuri pada krim pemutih

\begin{tabular}{cccc}
\hline Sampel & Uji KI & Uji Nyala Api & Hasil merkuri \\
\hline P1 & + & + & + \\
P2 & + & + & + \\
P3 & + & + & + \\
P4 & + & + & + \\
P5 & + & + & + \\
P6 & + & + & + \\
P7 & - & - & - \\
P8 & + & + & + \\
P9 & - & - & + \\
P10 & + & + & - \\
P11 & - & - & - \\
P12 & - & - & +
\end{tabular}

Keterangan: (+) mengandung merkuri, (-) tidak mengandung merkuri

\section{Uji Kualitatif Hidrokuinon}

Analisis kualitatif hidrokuinon dilakukan dengan uji pereaksi warna $\mathrm{FeCl}_{3}$. Pada uji pereaksi warna $\mathrm{FeCl}_{3}$, sampel positif mengandung hidrokuinon apabila terjadi perubahan warna menjadi hijau sampai hitam.

Senyawa hidrokuinon akan membentuk senyawa kompleks berwarna hijau sampai hitam (pada kondisi asam) apabila ditambah dengan larutan pereaksi $\mathrm{FeCl}_{3}$. Hasil yang didapat pada pengujian menggunakan $\mathrm{FeCl}_{3}$ yaitu sampel krim P1, P2, P4, P5, P6, P8, P10 berubah warna menjadi hitam, sampel krim P3 berubah warna menjadi jingga, sampel P7, P9, P11 dan P12 berubah warna menjadi kuning. Berdasarkan hasil tersebut dapat dinyatakan bahwa ada delapan sampel yang positif mengandung hidrokuinon yaitu sampel krim P1, P2, P3, P4, P5, P6, P8, dan P10 (Gambar 1). 


\section{Uji Kuantitatif}

Analisis kuantitatif bertujuan untuk mengetahui kadar suatu analit dalam sampel, dalam penelitian ini yaitu untuk mengetahui kadar hidrokuinon dalam krim pemutih. Senyawa hidrokuinon perlu diuji secara kuantitatif, karena berdasarkan BPOM (BPOM, Peraturan Kepala Badan Pengawas Obat dan Makanan Repubkik Indonesia Nomor HK.03.1.23.11.07331, 2011) masih diperbolehkan penggunaannya pada kosmetik dengan kadar $\leq 0,02 \%$, sehingga untuk membuktikan apakah sampel krim pemutih dalam penelitian ini masih boleh dipergunakan atau tidak.
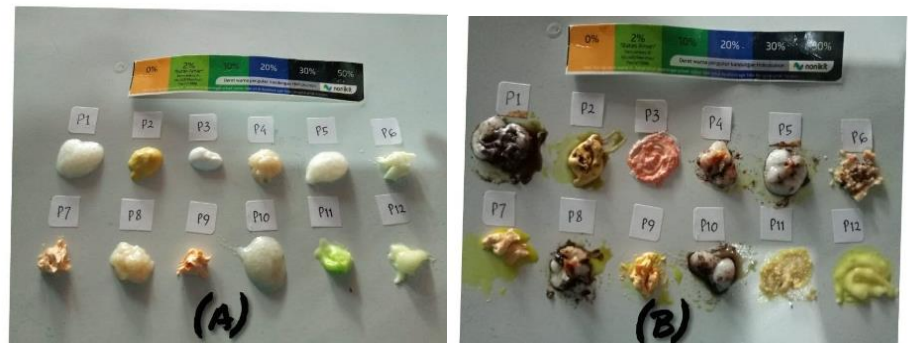

Gambar 1. Uji pereaksi warna $\mathrm{FeCl}_{3}$ krim pemutih: (A) Sebelum diberi pereaksi warna $\mathrm{FeCl}_{3}$, (B) Setelah diberi pereaksi warna $\mathrm{FeCl}_{3}$

Penetapan kadar hidrokuinon dilakukan dengan menggunakan instrumen bertujuan agar hidrokuinon dapat dipisahkan dari senyawa lain yang ada di dalam krim. Senyawa lain yang terdapat di dalam krim antara lain basis krim dan zat aktif yang ada di dalam krim. Penyerapan (absorpsi) sinar UV-Vis pada umumnya dihasilkan oleh eksitasi elektron-elektron ikatan, akibatnya panjang gelombang pita yang mengabsorbsi dapat dihubungkan dengan ikatan yang mungkin ada dalam suatu molekul. Elektron phi $(\pi)$ terdapat dalam ikatan rangkap dan pada struktur hidrokuinon memiliki ikatan rangkap. Untuk memungkinkan terjadinya transisi $\pi \rightarrow \pi^{*}$ senyawa tertentu harus mempunyai gugus fungsional yang tidak jenuh sehingga ikatan rangkap dalam gugus tersebut memberikan orbital phi yang diperlukan. Jenis transisi ini merupakan transisi yang paling cocok untuk analisis senyawa dengan panjang gelombang antara $200-700$ nm (Gandjar \& Rohman, 2007).

Panjang gelombang optimum hidrokuinon yang diperoleh dari larutan standar berada pada panjang gelombang $290 \mathrm{~nm}$ (Gambar 2). Tujuan pengukuran dari panjang gelombang maksimum adalah untuk mengetahui serapan optimum dari hidrokuinon, selanjutnya panjang gelombang ini akan digunakan untuk mengukur absorban sampel. 


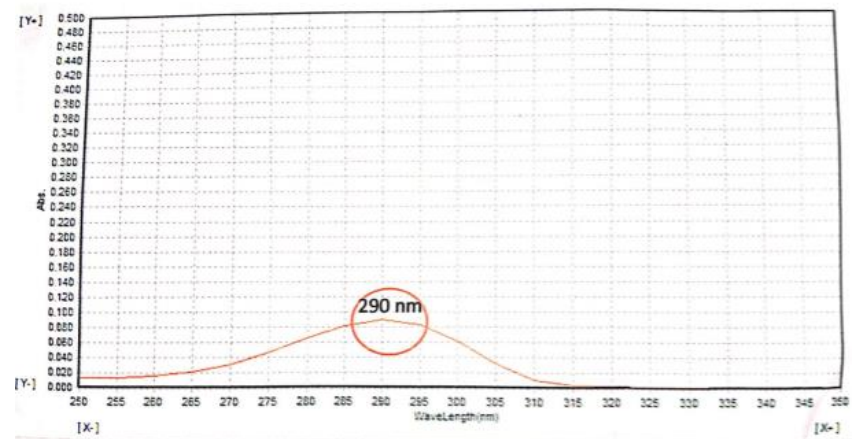

Gambar 2. Panjang gelombang optimum standar hidrokuinon

Larutan standar hidrokuinon dibuat variasi konsentrasi yaitu $5 \mathrm{ppm}, 10 \mathrm{ppm}, 15$ ppm, 20 ppm, 25 ppm, dan 30 ppm sebagai kurva kalibrasi dan etanol sebagai blanko (Tabel 2).

Tabel 2. Absorbansi variasi konsentrasi standar hidrokuinon

\begin{tabular}{ccc}
\hline No & Konsentrasi (ppm) & Absorbansi \\
\hline 1 & 5 & 0,089 \\
2 & 10 & 0,118 \\
3 & 15 & 0,232 \\
4 & 20 & 0,442 \\
5 & 25 & 0,564 \\
6 & 30 & 0,617 \\
\hline
\end{tabular}

Nilai absorbansi yang diperoleh dari sampel yaitu sampel P1 $=2,140$; sampel P2 $=2,117$; sampel P3 $=0,002$; sampel P4 =0,001; sampel P5 =0,013; sampel P6 = 0,055 ; sampel P7 $=0,316$; sampel P8 $=0,487$; sampel P9 $=0,080$; sampel P10 $=2,586$; sampel P11 = 0,850; dan sampel P12 = 0,820.

Berdasarkan pengukuran antara nilai absorabnsi dan konsentrasi diperoleh persamaan linier $\mathrm{Y}=\mathrm{ax}+\mathrm{b}$ dengan $\mathrm{Y}=0,0239 \mathrm{x}-0,0751$ (Gambar 3). Nilai $\mathrm{Y}$ adalah absorbansi, nilai a adalah slope (kemiringan), nilai $\mathrm{x}$ adalah konsentrasi sampel dan $\mathrm{b}$ adalah intersep.

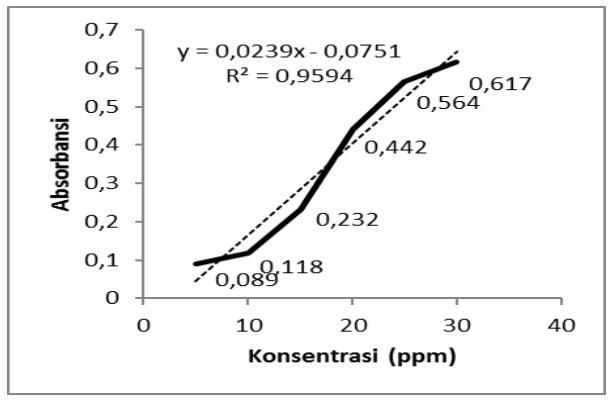

Gambar 3. Kurva kalibrasi standar hidrokuinon 
Penetapan kadar hidrokuinon dilakukan dengan menggunakan instrumen Spektrofotometer UV-Vis. Panjang gelombang optimum hidrokuinon yang diperoleh dari larutan standar berada pada panjang gelombang $290 \mathrm{~nm}$. Larutan standar hidrokuinon dibuat 6 variasi konsentrasi dan diperoleh persamaan kurva kalibrasi $\mathrm{Y}=$ 0,0239x - 0,0751 (Gambar 3). Hasil yang diperoleh dari pengujian kadar pada sampel krim pemutih menggunakan persamaan kurva kalibrasi, kemudian kadar sampel dihitung dengan rumus:

$$
\mathrm{K}=\frac{X X V X V P}{B S}
$$

Keterangan :

$\begin{array}{llll}\mathrm{K} & \text { : Kadar hidrokuinon dalam sampel } & \mathrm{V} & \text { : Volume sampel }(\mathrm{mL}) \\ \mathrm{X} & \text { : Konsentrasi sampel }(\mathrm{ppm}) & \mathrm{VP} & \text { : Faktor pengencer }(\mathrm{mL}) \\ \mathrm{BS} & \text { : Berat sampel }(\mathrm{mg}) & & \end{array}$

Sampel yang positif mengandung hidrokuinon adalah 12 sampel dengan kadar hidrokuinon sebagaimana ditunjukkan pada Tabel 3.

Tabel 3. Kadar Hidrokuinon pada Krim Pemutih

\begin{tabular}{ccc}
\hline Sampel & Absorbansi & Konsentrasi \pm SD $(\mathbf{p p m})$ \\
\hline P1 & 2,140 & $0,735 \pm 0,006$ \\
P2 & 2,117 & $0,727 \pm 0,005$ \\
P3 & 0,002 & $0,025 \pm 0,003$ \\
P4 & 0,001 & $0,021 \pm 0,002$ \\
P5 & 0,013 & $0,030 \pm 0,009$ \\
P6 & 0,055 & $0,044 \pm 0,010$ \\
P7 & 0,316 & $0,131 \pm 0,040$ \\
P8 & 0,487 & $0,188 \pm 0,041$ \\
P9 & 0,080 & $0,002 \pm 0,001$ \\
P10 & 2,586 & $0,840 \pm 0,592$ \\
P11 & 0,850 & $0,039 \pm 0,006$ \\
P12 & 0,820 & $0,030 \pm 0,004$ \\
\hline
\end{tabular}

Berdasarkan Peraturan Kepala Badan Pengawasan Obat dan Makanan nomor KH.03.1.23.08.11.07517 tahun 2011 tentang Persyaratan Teknis Bahan Kosmetika Hidrokuinon telah dilarang digunakan sebagai pemutih dalam kosmetik. Hidrokuinon hanya digunakan sebagai kosmetik untuk kuku artifisial dengan kadar 0,02\% (200 ppm) (BPOM, Peraturan Kepala Badan Pengawas Obat dan Makanan Repubkik Indonesia Nomor HK.03.1.23.11.07331, 2011). Hidrokuinon digunakan secara topikal sebagai agen depigmentasi untuk kulit dalam kondisi hiperpigmentasi cloasma (malesma), bintik -bintik dan lentigines (Sweeetman, 2009). Mekanisme efek toksik hidrokuinon terhadap melanosit (sel tempat sintesis melanin/pigmen hitam pada kulit) dan melalui penghambatan melanogenesis (proses pembentukan melanin). 
Validasi Metode

Penentuan linearitas

Linearitas menunjukkan kemampuan suatu metode analisis untuk memperoleh hasil pengujian yang sesuai dengan konsentrasi analit dalam contoh pada kisaran konsentrasi tertentu. Berdasarkan Hukum Lambert-Beer, absorbansi berbanding lurus dengan konsentrasi. Hubungan linear yang ideal dicapai jika nilai $b=0$ dan $r=+1$ atau -1 tergantung pada arah garis. Nilai koefisien korelasi yang memenuhi persyaratan diharapkan mendekati 1(Harmita, 2006). Linearitas yang didapatkan pada penelitian ini adalah $\mathrm{Y}=0,0239 \mathrm{x}-0,0751$ dengan menghasilkan koefisien korelasi ( $\mathrm{r}$ ) sebesar 0,9594. Nilai koefisien korelasi yang mendekati 1 menunjukkan adanya hubungan yang linear antara absorbansi yang terukur dengan konsentrasi analit.

Presisi

Presisi merupakan ukuran tingkat ketidakpastian hasil analisis. Uji presisi dilakukan dengan metode pengulangan, sehingga diperoleh ketelitian yang tinggi. Ketelitian dinyatakan dengan nilai RSD (Relative Standard Deviasion). Semakin kecil nilai RSD yang diperoleh, maka ketelitiannya semakin tinggi dan sebaliknya. Semakin besar nilai RSD yang diperoleh maka ketelitiannya semakin rendah. Hasil presisi yang diperoleh dari penelitian ini adalah $0,872 \%$. Nilai RSD menunjukkan $\leq 1 \%$, artinya metode yang digunakan sangat teliti.

Akurasi

Akurasi (kecermatan) adalah kedekatan hasil pengukuran dalam sampel yang diperoleh dari suatu metode dibandingkan kadar analit yang sebenarnya (Harmita, 2006). Kecermatan metode ini dapat dilihat dari persen perolehan kembali (\% recovery). Ratarata persen perolehan kembali yang diperoleh sebesar 97,5\%.

Syarat akurasi yang baik adalah 96-105\% dan beberapa berpendapat antara 80$120 \%$. Hal ini dikarenakan semakin kompleks penyiapan sampel dan semakin sulit metode analisis yang digunakan maka nilai perolehan kembali yang diperoleh semakin rendah atau kisaran semakin lebar (Harmita, 2006).

\section{LOD dan LOQ}

Limit of Detection (LOD)/Batas deteksi merupakan batas minimum suatu analit yang dapat dideteksi, sedangkan Limit of Quantitation (LOQ)/batas kuantisasi merupakan batas minimum analit yang dapat dihitung kadarnya (Mulja \& Hanwar, 2003). Perhitungan nilai LOD dan LOQ dilakukan secara statistik melalui garis regresi linier dari kurva kalibrasi. Batas deteksi/LOD alat untuk hidrokuinon adalah 3,373 ppm, sedangkan batas kuantitasinya/LOQ adalah 6,704 ppm.

\section{SIMPULAN}

Berdasarkan penelitian yang telah dilakukan dapat disimpulkan bahwa hasil uji kualitatif pada 12 sampel krim pemutih, ada 8 sampel yang positif mengandung merkuri dan hidrokuinon. Hasil uji kuantitatif dengan menggunakan instrumen Spektrofotometer UV-Vis 12 sampel positif mengandung hidrokuinon dengan kadar P1 0,0735 $\pm 0,006$

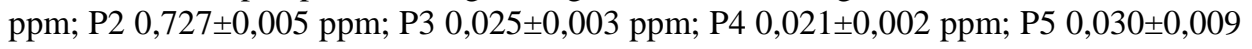

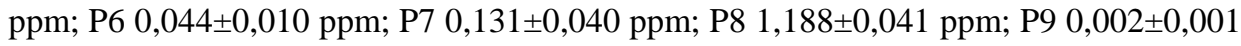

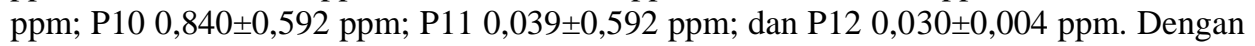
perolehan nilai presisi 0,872 \%, akurasi 97,5 \%, LOD 3,373 ppm dan LOQ 6,704 ppm. 


\section{DAFTAR RUJUKAN}

Arifiyana, D., Harjanti., Sri, Y., Ebtavanny. \& Gusti, T. (2019). Analisis Kuantitatif Hidrokuinon pada Produk Kosmetik Krim Pemutih yang Beredar di Wilayah Surabaya Pusat dan Surabaya Utara dengan Metode Spektrofotometri UV-Vis. Akta Kimia Indonesia, 4(2), 62-68.

Armin, F., Zulharmita. \& Firda, D. R. (2013). Identifikasi dan Penetapan Kadar Merkuri $(\mathrm{Hg})$ dalam Krim Pemutih Kosmetika Herbal Menggunakan Spektrofotometri Serapan Atom (SSA). Jurnal Sains dan Teknologi Farmasi, 18(1), 28-34.

Astuti D.W., Prasetya, H. R. \& Irsalina, D. (2016). Identifikasi Hidroquinon pada Krim Pemutih Wajah yang Dijual di Minimarket Wilayah Minomartani, Yogyakarta. Journal of Agromedicine and Medical Sciences, 2 (1),13-19.

Badan POM RI. (2008). Bahan Berbahaya dalam Kosmetik: Kosmetik Pemutih (Whitening). Jakarta: Edisi Agustus 2008 Naturakos Vol. III No.8.

Badan POM RI. (2011). Peraturan Kepala Badan Pengawas Obat dan Makanan Republik Indonesia Nomor HK.03.1.23.08.11.07331 Tahun 2011 Tentang Metode Analisis Kosmetika. Jakarta

Chakti, A. S., Simaremare, E. S. \& Pratiwi, R. D. (2019). Analisis Merkuri dan Hidrokuinon pada Krim Pemutih yang Beredar di Jayapura. Jurnal Sains dan Teknologi, 8(1), 1-11.

Draelos, Z. D. \& Thaman, L. A. (2005). Cosmetic Formulation of Skin Care Products. United States of America: Taylor and Francis Group.

Gandjar, I. G., \& Rohman, A. (2007). Kimia Farmasi Analisis. Yogyakarta: Pustaka Pelajar.

Harmita. (2006). Analisis Kuantitatif Bahan Baku dan Sediaan Farmasi. Jakarta: Departemen Farmasi FMIPA Universitas Indonesia.

Hermawati, A. H. \& Lathifah, Q. A. (2019). Uji Kualitatif Merkuri pada Krim Pemutih Wajah yang Tidak Terdaftar Badan Pengawas Obat dan Makanan di Kabupaten Tulungagung. Borneo Journal of Medical Laboratory Technology, 1(2), 57-61.

Mulja, M., \& Hanwar, D. (2003). Prinsip-prinsip Cara Berlaboratrium yang Baik (Good Laboratory Practice). Surabaya: Majalah Farmasi Airlangga.

Parengkuan, K.., Fatimawali. \& Citraningtyas, G. (2013). Analisis Kandungan Merkuri pada Krim Pemutih yang Beredar di Kota MANADO. PHARMACON: Jurnal Ilmiah Farmasi, 2(1), 62-68.

Sweetman, S. C. (2009). Martindale: The Complete Drug Reference. London: Pharmaceutical Press.

Syafnir, L. \& Putri, A. P. (2011). Pengujian Kandungan Merkuri dalam Sediaan Kosmetik dengan Spektrofotometri Serapan Atom. Prosiding SNaPP: Sains dan Teknologi, 2(1), 71-78.

Vogel. (1985). Analisis Anorganik Kualitatif Makro dan Semimakro. Jakarta: PT. Kalman Media Pustaka.

Vouk V. (1986). General Chemistry of Metals. In: Freiberg L., Nordberg G.F., and Vouk V.B (Eds). Handbook on the Toxicology of Metals. New York: Elsevier.

Westerhof W \& Kooyers TJ. (2005). Hydroquinone and Its Analogues in DermatologyA Potential Health Risk. Journal Of Cosmetic Dermatology, 4(2), 55-59. 